\title{
Cartazes de junho de 2013 em Belo Horizonte: funcionamento das formas de enunciação compartilhadas
}

\author{
Renan Belmonte Mazzola* \\ Universidade Vale do Rio Verde \\ Recebido em: 03/04/2019 \\ Aceito em: 21/11/2019
}

\begin{abstract}
Resumo: Este artigo objetiva analisar os cartazes empunhados nos protestos de junho de 2013, em Belo Horizonte, sob a ótica dos conceitos de "particitação" e "hiperenunciador" tal como constam em Maingueneau (2005). Por isso, este trabalho se filia à análise do discurso de linha francesa e interroga os regimes de enunciação compartilhada que integram os sujeitos enunciadores na cena "manifestação política". A partir da análise de 12 cartazes que compoem nosso corpus, demonstramos que esses enunciados apresentam elementos linguísticodiscursivos que sustentam a identidade de uma coletividade e manifestam um ponto de vista comum, que valida essa cena enunciativa.
\end{abstract}

Palavras-chave: Protestos de Junho. Cartaz. Manifestação. Discurso.

Abstract: This paper aims to analyze the posters held in the protests of June 2013, in Belo Horizonte, from the perspective of the concepts of "particitation" and "hyperenunciator" (Maingueneau, 2005). Therefore, this work is based on the discourse analysis of the French line and it questions the shared enunciation structures that integrate the enunciating subjects in the "political manifestation" scene. From the analysis of 12 posters that make up our corpus, we show that these statements present linguistic-discursive elements that support the identity of a collectivity and manifest a common point of view, which validates this enunciative scene.

Keywords: Protests from June. Poster. Manifestation. Discourse.

Résumé: Cet article vise à analyser les affiches utilisées lors des manifestations de juin 2013 à Belo Horizonte, sous l'angle des concepts de "particitation" et d "hyperenunciateur" tels qu'ils apparaissent dans Maingueneau (2005). Ce travail est donc basé sur l'analyse du discours de ligne française et interroge les régimes d'énonciation partagés qui intègrent les sujets énonceateurs dans la scène "manifestation politique". À partir de l'analyse de 12 affiches constituant notre corpus, nous montrons que ces déclarations présentent des éléments linguistiques-discursifs qui soutiennent l'identité d'une collectivité et manifestent un point de vue commun, qui valide cette scène énonciative.

Mots-clés: Manifestations de Juin. Affiche. Manifestation. Discours.

\section{Introdução}

O quadro político do Brasil de hoje foi forjado, em grande medida, por uma sucessão de acontecimentos derivados dos Protestos de Junho de 2013: entre eles, testemunhamos, num primeiro momento, a deposição - por meio de impeachment - da então presidente Dilma Rousseff, do PT; a ascensão em 2016 da figura controversa de 
Michel Temer, do MDB, que governou o Brasil por mais de dois anos; e por fim, a eleição em 2018 do candidato de perfil conservador Jair Bolsonaro, do PSL, consagrado Presidente da República pela maioria dos votos dos brasileiros.

Por essa razão, os Protestos de Junho e seus desdobramentos precisam ser mais estudados por diversos campos do conhecimento, para que melhor se compreendam as conjunturas de sua emergência e de sua difusão, que provocaram consequências importantes para a configuração discursiva política que o Brasil apresenta hoje.

Durante os dias de junho de 2013, o Brasil viu emergir uma série de protestos contra o aumento das passagens no transporte público. Dia após dia, essas manifestações ganhavam corpo e destaque nas mídias de todo o país. Como em todo protesto, percebia-se aumentar a tensão entre os manifestantes e a polícia, entre os manifestantes e a mídia, entre os manifestantes e o governo, e também entre os próprios grupos de manifestantes.

Na cobertura dos protestos de junho pela mídia, muita atenção foi dada aos cartazes empunhados pelos manifestantes nas ruas de todo o país. Esses cartazes de manifestação compunham o discurso das ruas e apresentavam, no território nacional, regularidades enunciativas que contribuíam para a construção do acontecimento discursivo das Jornadas de Junho.

Baseando-se no aparato teórico-metodológico da Análise do Discurso de linha francesa, este artigo objetiva analisar o funcionamento enunciativo e discursivo dos cartazes empunhados durante os Protestos de Junho de 2013, a partir das noções de hiperenunciador e particitação, tal como constam nos trabalhos de Dominique Maingueneau, em especial no artigo publicado na revista Langages n. 156, cuja versão em português foi publicada pela revista brasileira Polifonia (cf. MAINGUENEAU, 2005).

Diante dessa perspectiva, colocamos as seguintes perguntas de pesquisa: a) como esses enunciados militantes mobilizam o aparelho da enunciação? b) como esses enunciados constroem uma identidade de grupo?

As análises serão realizadas sobre um recorte de nosso corpus de pesquisa, composto de diversos cartazes empunhados nos Protestos de Junho de 2013 em Belo Horizonte e veiculados pelo jornal $O$ Tempo durante o período de 18 a 26 de junho de 2013. 
Metodologicamente, a busca e a coleta dos enunciados dos cartazes foram feitas a partir das seguintes etapas:

(i) utilização do repositório online de notícias do jornal O Tempo para buscas, utilizando-se as palavras-chave "protestos", "junho" e "2013";

(ii) recorte temporal das notícias entre 18 e 26 de junho de 2013;

(iii) seleção de três grandes galerias de fotos sobre os acontecimentos, disponíveis em:

a. <https://www.otempo.com.br/galeria-de-fotos/manifestacoes-em-bh-18de-junho-1.665625>;

b. <https://www.otempo.com.br/galeria-de-fotos/manifestacoes-em-bh-2ode-junho-1.667628>;

c. <https://www.otempo.com.br/galeria-de-fotos/manifestacoes-em-belohorizonte-26-de-junho-de-2013-1.670709>;

(iv) Transcrição de todos os cartazes registrados nas fotografias das três galerias;

(v) Seleção dos cartazes mais representativos para as análises.

Este artigo é composto de quatro partes, além desta introdução e das considerações finais: a primeira, intitulada "Protestos de Junho: acontecimentos múltiplos” discute o nascimento e o histórico desses movimentos; a segunda, intitulada "O aparelho enunciativo", busca a influência de Benveniste na teoria de Charaudeau e Maingueneau; a terceira, intitulada "Particitação e hiperenunciação" explora as particularidades das formas de enunciação compartilhadas; a quarta, intitulada "Particitações militantes", articula o pensamento de Maingueneau com o funcionamento enunciativo dos cartazes de protestos.

\section{Protestos de Junho: acontecimentos múltiplos}

No início de junho de 2013, o preço das passagens de ônibus, metrô e trens foi reajustado em São Paulo - passou de R\$3,oo para R\$3,20. Esse aumento também foi aplicado em outras capitais e regiões metropolitanas do país, desencadeando uma série de protestos contra o aumento de R $\$ 0,20$ nas passagens. Em São Paulo, os protestos iniciaram-se no dia 6 de junho e foram noticiados pela mídia no dia 7. Desde então, eles alcançaram uma dimensão nacional e levaram dezenas de milhares de pessoas às 
ruas. Os primeiros agentes dos protestos em São Paulo foram os integrantes do Movimento Passe Livre (MPL), que reivindicavam a redução dos R $\$ 0,20$ no preço das passagens. Após sucessivos confrontos com a polícia e a adesão de uma grande parcela de brasileiros (250 mil pessoas só em São Paulo; 12 capitais brasileiras e 16 cidades do interior foram às ruas no dia 17 de junho - o dia em que os ativistas tomaram as lajes do Congresso Nacional em Brasília'1), as manifestações ganharam ainda outras pautas, refletidas nos cartazes empunhados por ativistas e registradas pela mídia em toda a extensão do território brasileiro. Algumas delas são: oposição à PEC-37, aos gastos com a Copa do Mundo de 2014, à corrupção de nossos governantes; reivindicação de melhorias nos serviços públicos, como saúde, educação, segurança, etc.

Considera-se que os protestos de junho de 2013 constituíram a maior mobilização popular desde o impeachment do ex-presidente Fernando Collor, em 1992. Em função da quantidade de pessoas e da importância das reivindicações, muitos portais $^{2}$ de notícias atribuíram à data (17 de junho) uma importância histórica. Esses 21 anos que separam os Caras-Pintadas (1992) dos Protestos de Junho (2013) correspondem à mudança de uma geração: uma parcela expressiva dos manifestantes de 2013 nasceu no início dos anos 1990. Os estudantes que saíram às ruas em 1992 possuíam em 2013 a idade dos pais dos estudantes que se mobilizaram nos inícios dos protestos de junho.

Os protestos do mês de junho de 2013 são complexos e multifacetados: começaram com uma pauta específica - a redução de $\mathrm{R} \$ 0,20$ na tarifa dos transportes públicos - e começaram a ganhar outros contornos, outras pautas, outros movimentos, à medida que os protestos cresceram em número de manifestantes e em visibilidade midiática, a partir dos grandes veículos de comunicação impressos, televisivos, on-line e a partir de uma mídia alternativa (Mídia Ninja) que se opunha aos grandes veículos (Globo, Veja, Folha de S. Paulo, etc.). Em comparação com o movimento dos CarasPintadas, os protestos de junho de 2013 foram organizados essencialmente a partir das redes sociais. Esse fenômeno - a mobilização de milhares de pessoas a partir do Facebook - representa a essência da arquitetura dos protestos de junho.

1 Fonte:<http://g1.globo.com/brasil/noticia/2013/06/protestos-pelo-pais-reunem-mais-de-250milpessoas.html>. Acesso em 10 fev. 2015.

2Fonte:<http://www.revistadehistoria.com.br/secao/reportagem/o-protesto-de-17-de-junho-de-2013>. Acesso em 10 fev. 2015. 
Para melhor compreendermos o funcionamento desses grupos militantes que empunhavam cartazes no contexto desses protestos, e, particularmente, o funcionamento enunciativo e discursivo desses enunciados políticos, iremos, a seguir, traçar uma breve trajetória dos estudos de enunciação no campo da linguística.

\section{O aparelho enunciativo}

Para Maingueneau (2005, p. 77), a particitação é um sistema de citação singular, uma categoria pragmática que atravessa vários gêneros discursivos: "Esses sistemas não são tipos propriamente ditos, ou gêneros de discurso, nem feixes compactos de marcadores lingüísticos; são, sim, uma certa forma de mobilizar o aparelho enunciativo".

Para iniciarmos nossas discussões, é preciso compreender antes como funciona o aparelho enunciativo tal como ele foi trabalhado e retrabalhado no campo da linguística. Esse aparelho foi estudado por Benveniste (2005), em seus volumes dos Problemas de linguística geral. Para o autor francês, principal expoente da teoria da enunciação,

\footnotetext{
Uma teoria linguística da pessoa verbal só pode constituir-se sobre a base das oposições que diferenciam as pessoas, e se resumirá inteiramente na estrutura dessas oposições. Para desvendá-la, poderemos partir das definições empregadas pelos gramáticos árabes: Para eles, a primeira-pessoa é almutakallimu, "aquele que fala"; a segunda, al-muhatabu, "aquele a quem nos dirigimos"; mas a terceira é al-ya ibu, "aquele que está ausente" (BENVENISTE, 2005, p. 250).
}

Assim, para formular a teoria da subjetividade na linguagem, associada à enunciação, Benveniste parte das definições dos gramáticos árabes: "aquele que fala”; “a quem nos dirigimos" e "aquele que está ausente”. Esta última dá origem à noção de "não-pessoa", que a gramática tradicional chama de "terceira pessoa”. Da leitura dessas linhas de Problemas de linguística geral I, podemos extrair a seguinte síntese esquemática:

EU: pessoa subjetiva

TU: pessoa não-subjetiva

ELE: não pessoa (terceira-pessoa) 
A partir desse estudo de Benveniste, conclui-se que a subjetividade na língua se dá pela pessoa do discurso, isto é, pelas pessoas da enunciação, que são eu-tu. É importante notar que, no diálogo, a referência da subjetividade alterna-se cada vez que cada um dos interlocutores toma a palavra, isto é, cada vez que alguém toma a palavra se constitui o "eu" da enunciação e a subjetividade se produz. Por isso dizemos que há uma alternância da subjetividade no diálogo e que eu-tu se constituem como as pessoas efetivas do discurso. Portanto, a subjetividade na língua pode ser explicada a partir dos pronomes pessoais ou das pessoas verbais.

Na esteira da teoria de Benveniste (2005), Charaudeau (2006), no campo da semiolinguística - em seu livro Discurso político, particularmente no capítulo "Imagem dos atores políticos" - elenca alguns procedimentos enunciativos que permitem analisar o ethos de oradores na construção de seu discurso nos comícios ou na tevê. A partir desses procedimentos, Charaudeau nos mostra: a) como aquele que fala colocase em cena (o que ele chama de enunciação elocutiva); b) como aquele que fala implica seu interlocutor na enunciação (enunciação alocutiva); e c) como se apresenta o que é dito como se ninguém estivesse implicado (enunciação delocutiva).

Como exemplo da enunciação elocutiva, construída com ajuda dos pronomes pessoais de primeira pessoa acompanhados de verbos modais, temos: "Eu estou certo de que juntos venceremos”3 (CHARAUDEAU, 2006, p. 174, grifos do autor). Aqui, percebemos a implicação do orador no enunciado e seu ponto de vista.

Como exemplo da enunciação alocutiva, construída com a ajuda dos pronomes pessoais de segunda pessoa, juntamente com os verbos modais, temos: "Meus caros compatriotas...” (CHARAUDEAU, 2006, p. 176). Para o autor (p. 176), esse tipo de enunciação revela, ao mesmo tempo, "a implicação do interlocutor, o lugar que lhe designa o locutor e a relação que se estabelece entre eles”. Como exemplo da enunciação delocutiva, construída como se o que foi dito não fosse da responsabilidade de nenhum dos interlocutores presentes, temos: "O futuro de nosso país está nas mãos do povo" (CHARAUDEAU, 2006, p. 178). Essa forma de enunciação cria a impressão de que quem fala é "a verdade" ou "uma voz terceira” que não são nem o locutor nem o interlocutor do diálogo.

${ }^{3}$ Estes exemplos e os seguintes são citados pelo próprio Charaudeau (2006). 
Esses procedimentos enunciativos também podem ser deslocados para as análises dos cartazes empunhados pelos manifestantes no contexto dos Protestos de Junho, pois notamos neles esses três funcionamentos apontados por Charaudeau. Vejamos alguns exemplos (cujas grafias foram mantidas tal como constam nos próprios cartazes):

(1) DESCULPEM O TRANSTORNO ESTAMOS MUDANDO O BRASIL (O tempo, 18.06.2013). 4

(2) QUEREMOS UM BASTA NESSA CORRUPÇÃO (O tempo, 20.06.2013). ${ }^{5}$

(3) PARE DE SÓ RECLAMAR, VEM PRA RUA LUTAR (O tempo, 20.06.2013). ${ }^{6}$

(4) \#FALTAVOCÊAQUI (O tempo, 18.06.2013).7

(5) ENQUANTO A BOLA ROLA FALTA SAÚDE FALTA ESCOLA!! (O tempo, 20.06.2013)..$^{8}$

(6) TEM TANTA COISA ERRADA QUE NEM CABE EM UM CARTAZ (O tempo, 20.06.2013).9

Os exemplos (1) e (2) revelam um tipo de enunciação elocutiva, expressa com a ajuda dos pronomes pessoais de primeira pessoa do plural nós, resgatados pela morfologia verbal. A função desse tipo de enunciação é implicar o orador na cena. Nesses dois exemplos, o pronome nós, implícito em "estamos mudando o Brasil”, "Queremos um basta nessa corrupção" é de natureza exclusiva, isto é, esse nós exclui o interlocutor da cena manifestação, fazendo com que entendêssemos esse enunciado como Nós, que estamos aqui, "estamos mudando o Brasil" e "queremos um basta nessa corrupção"; diferente de vocês, que estão aí, que "não estão mudando o Brasil" e "não querem um basta nessa corrupção". Esse enunciado produz um ethos de compromisso ou engajamento.

\footnotetext{
4 Disponível em: <https://www.otempo.com.br/galeria-de-fotos/manifestacoes-em-bh-18-de-junho1.665625>. Acesso em: 01 mar. 2019.

5 Disponível em: <https://www.otempo.com.br/galeria-de-fotos/manifestacoes-em-bh-20-de-junho1.667628>. Acesso em: 01 mar. 2019.

6 Disponível em: <https://www.otempo.com.br/galeria-de-fotos/manifestacoes-em-bh-20-de-junho1.667628>. Acesso em: 01 mar. 2019.

7 Disponível em: <https://www.otempo.com.br/galeria-de-fotos/manifestacoes-em-bh-18-de-junho1.665625>. Acesso em: 01 mar. 2019.

8 Disponível em: <https://www.otempo.com.br/galeria-de-fotos/manifestacoes-em-bh-20-de-junho1.667628>. Acesso em: 01 mar. 2019.

9 Disponível em: <https://www.otempo.com.br/galeria-de-fotos/manifestacoes-em-bh-20-de-junho1.667628>. Acesso em: 01 mar. 2019.
} 
Os exemplos (3) e (4), por seu turno, revelam um tipo de enunciação alocutiva, expressa com a ajuda de pronomes pessoais de segunda pessoa, tendo por função a implicação do interlocutor na cena enunciativa. Assim, em "Pare só de reclamar, vem pra rua lutar" e "\#FALTAVOCÊAQUI", temos, respectivamente, o emprego dos imperativos pare e vem; e o emprego do pronome você. Esses elementos são dirigidos ao interlocutor e sob a forma de apelo ou incitação têm por objetivo trazer esse tu para a cena manifestação. A partir da modalidade de tratamento informal empregada nesses cartazes, constatamos que o locutor chama para a cena um interlocutor que pode ser um igual: "Pare (você) só de reclamar, vem (você) pra rua lutar". O ethos construído aqui é aquele da solicitação ou do desafio.

Por fim os exemplos (5) e (6) revelam a enunciação delocutiva, que coloca o assunto em primeiro plano e apaga os interlocutores no enunciado. É como se a palavra dada não pertencesse aos interlocutores. Os cartazes "Enquanto a bola rola falta saúde falta escola" e "Tem tanta coisa errada que nem cabe em um cartaz" afastam o locutor e o interlocutor do que está sendo enunciado e dão lugar a uma voz terceira que, entre outras possiblidades, diz: "Todos sabem que enquanto o país festeja a Copa do Mundo enfrentamos graves problemas na educação" e "Há muitas coisas que são motivo de descontentamento no Brasil”. É como se esses enunciados tivessem um valor em si. O ethos aqui construído pode ser aquele da consciência ou da constatação das mazelas brasileiras.

No eixo da subjetividade-objetividade estudado por Benveniste (2005) e apropriado à sua maneira por Charaudeau (2006), os quatro primeiro exemplos - (1), (2), (3) e (4) - estariam assentados sobre a subjetividade, uma vez que se referem às pessoas eu e tu do discurso, ao passo que os dois últimos exemplos - (5) e (6) estariam assentados sobre a objetividade, pois não há referência aos interlocutores.

\section{Particitação e hiperenunciação}

Após termos demonstrado o funcionamento do aparelho enunciativo, poderemos nos aprofundar nesses sistemas singulares de citação que Maingueneau denominou de particitações. Diferente da citação prototípica ou das formas do discurso relatado, em que percebemos a) o corte de um fragmento acompanhado da 
explicitação de sua fonte; b) a sobreposição de uma situação de comunicação sobre outra, de forma planejada; e c) as estratégias de modalização que ocorrem para mediar as distâncias do mundo que cita e do mundo citado; as formas de particitação, por sua vez, causam uma erosão nessas estruturas canônicas do aparelho enunciativo:

Nós focalizaremos aqui por um sistema de citação singular, a particitação, uma palavra-valise que funde "participação" e "citação". Essa categoria fundamentalmente pragmática atravessa vários gêneros, sem que, para isso, corresponda a um procedimento. Mutatis mutandis, poderíamos dizer que se trata de um procedimento comparável àquele dos lingüistas que, seguindo a linha de Benveniste (1966), distinguem vários sistemas enunciativos (ao menos dois), segundo a relação que se estabelece entre enunciado e situação de enunciação. Esses sistemas não são tipos propriamente ditos, ou gêneros de discurso, nem feixes compactos de marcadores lingüísticos; são, sim, uma certa forma de mobilizar o aparelho enunciativo, ao qual estão associados, de modo regrado, alguns gêneros de discurso e alguns marcadores lingüísticos (MAINGUENEAU, 2005, p. 76-77, grifos do autor).

Maingueneau (2005) explicita quatro configurações que definem o sistema de particitação. Em primeiro lugar, o sistema de particitação distancia-se dos procedimentos de citação canônicos pelo fato do enunciado particitado apresentar uma certa autonomia, um certo destacamento do restante da obra de que é parte. Em segundo lugar, essa citação deve ser reconhecida como tal pelos membros da comunidade em que circulam esse enunciado, sem a necessidade da remissão à fonte originária desse excerto. Em terceiro lugar, aquele que cita mostra sua adesão ao enunciado citado, pertencente a um Thesaurus de enunciados mais ou menos reconhecíveis para uma coletividade. Em quarto lugar, esse Thesaurus está associado à figura de um hiperenunciador, uma instância que enuncia antes e em outro lugar, responsável pela validação e pela adequação dos valores e dos fundamentos que regem determinadas estruturas sociais. Uma vez que a particitação está em contato direto com a variedade de situações sócio-históricas, Maingueneau (2005, p. 79) distingue diversas famílias dessas "citações sem autor". Vejamos quais são elas:

1. As particitações sentenciosas: o provérbio e o adágio jurídico.

2. As particitações gráficas: o destacamento, o humanismo e o Thesaurus bíblico.

3. As particitações de grupo: os militantes - aí incluídos o slogan e o canto dos torcedores - e as comunhões - aí incluídos a oração e os intérpretes.

4. O hiperenunciador com instâncias de enunciação complexas. 
Resumiremos cada uma delas a seguir, pois seu entendimento é fundamental para explorarmos mais detidamente a terceira delas: as particitações militantes. Para Maingueneau, então, as particitações sentenciosas apresentam um apagamento enunciativo mais evidente: na enunciação proverbial, "há o deslocamento entre aquele que profere o provérbio e aquele que garante sua veracidade.” (2005, p. 79). A proposição é assumida por duas instâncias de fala: o sujeito universal e depois eu. Ao enunciar um provérbio, há uma voz anterior, denominada sabedoria das nações, que valida o que está sendo dito por mim. O sujeito universal é justamente a doxa, essa sabedoria das nações que garante a validade do meu enunciado. Ao enunciar, tanto eu quanto meu interlocutor são englobados em uma dada comunidade: "Por sua própria enunciação, o particitador de um provérbio confere a si - e a seu alocutário (...) o estatuto de membro de uma comunidade." (MAINGUENEAU, 2005, p. 80). O adágio jurídico, por sua vez, também é um tipo de particitação que promove um pertencimento por meio de um Thesaurus em língua latina, que "reforçava o sentimento de pertencimento de seus usuários à comunidade de profissionais da justiça, cujo socioleto era, aliás, regularmente ridicularizado por produções satíricas.” (MAINGUENEAU, 2005, p. 8o). O adágio, por isso, foi se forjando ao longo do tempo como uma sentença moral de origem popular, um ditado que circula em determinadas ocasiões, como "Cartas têm mais credibilidade que testemunhos" e "Todos os delitos são pessoais", segundo os exemplos de Maingueneau (2005, p. 80).

As particitações gráficas são três: as citações conhecidas, o humanismo e o Thesaurus bíblico. São particitações que apresentam destaque gráfico. Em primeiro lugar temos as citações conhecidas que, para Maingueneau (2005, p. 82), são "enunciados curtos, facilmente memorizáveis, cujo significante e significado são extraídos de uma organização mais ou menos pregnante”. São espécies de fórmulas que sofrem destacamento de sua obra original e podem figurar em dicionários de citações, que passam a ser compartilhados por um determinado grupo. Podem ser frases conhecidas, provérbios ou aforismas. Em segundo lugar, há as citações humanistas, que são restritas à comunidade seleta "dos humanistas do século XVI, que se reuniam em torno de um Thesaurus. Em Montaigne, encontramos um grande número de citações em latim que são dadas sem autor: Cur non ut plenus vitae conviva recedis?" (MAINGUENEAU, 2005, p. 83). Trata-se de um regime de citação que, apesar de vir em 
itálico tipograficamente destacado, não apresenta autoria, pelo fato de a comunidade humanista ser tão próxima dessas fontes que se dispensa a necessidade de inserir o autor da citação. Em terceiro lugar, temos o Thesaurus bíblico, que coloca como hiperenunciador a figura de Deus ou de Cristo, que fala através de um único livro: a Bíblia sagrada. Nesse tipo de particitação, também há uma grande familiaridade entre os membros dessa comunidade religiosa, de forma a dispensar também a necessidade da referência à fonte. Para Maingueneau (2005, p. 86), “ao particitar os fragmentos do Thesaurus, os locutores mostram o Espírito que os habita. Essa prática leva logicamente ao desaparecimento das marcas do discurso citado: cabe ao leitor ou ao ouvinte reconhecê-lo".

As particitações de grupo são divididas em duas vertentes: as de comunhão e as militantes. Esse tipo de particitação implica locutores coletivos, e visa "à fusão imaginária dos indivíduos em um locutor coletivo que, por sua enunciação, institui e confirma o pertencimento de cada um ao grupo." (MAINGUENEAU, 2005, p. 87). As de comunhão visam à fusão entre os membros do grupo, como no momento de uma oração ou no momento do canto de estudantes de medicina. Para Maingueneau (2005, p. 91), ao pronunciar o Pai Nosso ou a Ave Maria, respectivamente atribuídos a Cristo e ao anjo Gabriel, “a comunidade se une em pensamento pela identificação com um hiperenunciador encarnado (o Cristo) cujo anjo é apenas um porta-voz".

\section{A particitação militante}

Para este trabalho, interessam-nos particularmente as particitações da militância, pertencentes às particitações de grupo. Essas particitações militantes implicam locutores também coletivos que, em cada enunciação isolada, institui e confirma o pertencimento de cada um no grupo. Diferentemente das orações, que visam à fusão dos membros de um grupo, as militantes reforçam a coesão de uma coletividade opondo-a a um exterior ameaçador (slogans, cantos de torcedores, gritos de guerra... e incluímos aqui os cartazes de protesto). Nessa coletividade, é preciso estabelecer uma distinção importante entre as várias instâncias que integram esse aparelho enunciativo. Cabe elencar:

(a) Os locutores empíricos, indivíduos que compõem o grupo; 
(b) $\mathrm{O}$ ator coletivo do qual eles participam: um partido, um conjunto de manifestantes, uma associação;

(c) O hiperenunciador que funda os diversos PDV expressos por esse ator: "a Esquerda”, “a Nação”, “o Clube”, etc. (MAINGUENEAU, 2005, p. 87).

Enquanto o ator coletivo tem por referente grupos de locutores que formam uma organização em um momento e lugar determinados, o hiperenunciador tem por referente entidades transcendentes, responsáveis e fontes do PDV. O slogan político, que integra o grupo das particitações militantes, tem por função ser repetido. Para Maingueneau (2005, p. 88), “a enunciação do slogan militante implica a existência de um locutor hostil ou indiferente frente ao qual se afirma o grupo. Neste caso, está-se em relação com um NÓS que supõe algo complementar, geralmente um concorrente no mesmo domínio".

Podemos entender mais claramente, agora, as condições enunciativas dos Protestos de Junho de 2013, que se caracterizaram por um grupo de manifestantes de origens variadas que se uniam em torno de uma questão comum. Essa questão em comum, bem entendido, foi se alterando ao longo do tempo, e as insatisfações em torno do aumento de $\mathbf{0 , 2 0}$ centavos nas passagens de transporte público foram se modificando para insatisfação contra os gastos públicos na Copa do Mundo, contra a “corrupção" do governo - mesmo que não se saiba muito bem o que isso quer dizer, uma vez que se passa de uma pauta muito específica (redução de o,20 centavos nas passagens) para uma pauta muito ampla (e enfrenta-se o risco de dissolução da pauta inicial).

A partir disso, analisaremos alguns cartazes militantes que, como foi discutido nas linhas acima, apresentam características de citação sem autor, mas que unem um grupo contra um exterior ameaçador ou indiferente - nessa ocasião, o governo brasileiro:

(7) Verás Que O Filho Teu Não Foge A Luta! (O tempo, 20.06.2013). ${ }^{10}$

(8) NAS ESCOLAS NAS RUAS CAMPOS CONSTRUÇÕES, SOMOS TODOS IGUAIS / BRAÇOS DADOS OU NÃO! (O tempo, 20.06.2013). ${ }^{11}$

(9) AFASTA DE MIM ESSE CALE-SE! (O tempo, 26.o6.2013). ${ }^{12}$

10 Disponível em: <https://www.otempo.com.br/galeria-de-fotos/manifestacoes-em-bh-18-de-junho1.665625>. Acesso em: 01 mar. 2019.

11 Disponível em: <https://www.otempo.com.br/galeria-de-fotos/manifestacoes-em-bh-20-de-junho1.667628>. Acesso em: 01 mar. 2019. 
Nesses cartazes, visualizamos claramente um regime enunciativo no qual a voz do outro perpassa a minha voz sem que eu precise atribuir-lhe a autoria, mas que, por outro lado, o locutor e o interlocutor reconhecem que a voz é de outrem.

Voltando às quatro configurações mencionadas por Maingueneau (2005), vemos que a) os enunciados citados nos cartazes são autônomos, uma vez que se destacaram do resto das canções às quais pertencem originalmente. b) Essas citações são conhecidas e reconhecidas como trechos do Hino Nacional Brasileiro, de Joaquim Osório e Francisco Manuel da Silva (cartaz 7); da canção Pra não dizer que não falei das flores, de Geraldo Vandré (cartaz 8); e da canção Cálice, de Chico Buarque e Gilberto Gil (cartaz 9). c) Os locutores mostram adesão ao enunciado citado, pelo fato dos três enunciados dos cartazes (7), (8) e (9) remeterem às resistências da opressão política, que por sua vez colocam os locutores nesse lugar resistente. d) Esses trechos compõem um Thesaurus da resistência e da luta política brasileira, mobilizado a todo instante em ocasiões de manifestação e protesto.

Aqui também se encontra a voz do hiperenunciador que atravessa cada um desses cartazes e valida os valores da luta. Poderíamos definir esse hiperenunciador como a voz do povo ou a oposição ao governo, embora saibamos que os Protestos de Junho são muito complexos e sofreram muitos desdobramentos ao longo do tempo, fazendo com que, ao seu final, conglomerasse vários partidos políticos e vários setores da sociedade em função de um sentimento geral de insatisfação. Vejamos os cartazes a seguir:

(10) NÓS LUTAMOS POR DIREITOS. NÓS LUTAMOS POR RESPEITO. (O Tempo, 20.06.2013)..$^{13}$

(11) “A CONSCIÊNCIA DO POVO DAQUI É O MEDO DOS HOMENS DE LÁ” (O tempo, 21.06.2013). ${ }^{14}$

Nesses cartazes, o espaço dos membros dos Protestos de Junho fica visivelmente separado daquele do Governo em função dos elementos dêiticos nós em contraposição com eles, no cartaz (10); e aqui em contraposição com lá, no cartaz (11). A característica

\footnotetext{
12 Disponível em: <https://www.otempo.com.br/galeria-de-fotos/manifestacoes-em-belo-horizonte-26de-junho-de-2013-1.670709>. Acesso em: 01 mar. 2019.

13 Disponível em: <https://www.otempo.com.br/galeria-de-fotos/manifestacoes-em-bh-20-de-junho1.667628>. Acesso em: 01 mar. 2019.

14 Disponível em: <https://www.otempo.com.br/galeria-de-fotos/manifestacoes-em-bh-20-de-junho1.667628>. Acesso em: 01 mar. 2019.
} 
dessa coletividade é construída simultaneamente pelas expressões nós e daqui da cena manifestação. $\mathrm{O}$ exterior ameaçador ou indiferente é resgatado pelas expressões eles não presente no enunciado (10), mas inferido - e lá - explícito no enunciado (11).

Esse hiperenunciador, que poderíamos nomear de opositor ao governo, reuniria em si não só os traços de luta por direitos e respeito (10), e de consciência do povo (11), mas de todas as outras marcas em todos os outros cartazes empunhados durante os Protestos, pois esses locutores coletivos devem apresentar uma identidade:

O hiperenunciador aparece como uma instância que, por um lado, garante a unidade e a validade da irredutível multiplicidade dos enunciados do Thesaurus e, por outro, confirma os membros da comunidade em sua identidade, pelo simples fato de eles manterem uma relação privilegiada com ele (MAINGUENEAU, 2005, p. 93, grifos do autor).

Da mesma forma como as pautas dos Protestos de Junho foram se ampliando ao longo do tempo, esse hiperenunciador também foi ficando mais amplo, até poder ser representado por um enunciado que cristalizaria o conjunto das reivindicações e, por sua vez, culminaria na dissolução dos Protestos:

(12) QUEREMOS UM BASTA NESSA CORRUPÇÃO (O tempo, 20.06.2013).15

Sob o "guarda-chuva" da corrupção, tudo e nada podia ser agora reivindicado. “Diferentemente da 'sabedoria das nações', que permanece estável, esse hiperenunciador varia em função da opção política dos agrupamentos.” (MAINGUENEAU, 2005, p. 89, grifos do autor). Se, ao cabo e ao final, os manifestantes não sabiam mais para que lutavam, o hiperenunciador anti-corrupção transforma-se em um vulto confortável para manifestações sem pautas específicas.

\section{Considerações finais}

Neste trabalho, procuramos demonstrar, com base no célebre texto de Maingueneau (2005), que a análise do funcionamento das formas de enunciação compartilhadas - entre elas, especificamente, o funcionamento dos cartazes de uma manifestação específica - pode nos trazer resultados interessantes. Entre eles,

15 Disponível em: <https://www.otempo.com.br/galeria-de-fotos/manifestacoes-em-bh-20-de-junho1.667628>. Acesso em: 01 mar. 2019. 
primeiramente, como o sistema de participação e citação (a particitação) confere um sentimento de grupo no contexto de uma manifestação política.

Em segundo lugar, observamos as nuances da figura do hiperenunciador, essa voz que fala antes e em outro lugar e que confere a validação de todos os enunciados compartilhados em uma coletividade. Nos Protestos de Junho, o hiperenunciador foi se ampliando de tal forma que, ao final, foi perdendo seus traços distintivos, culminando na dissolução das manifestações, ou, como dizem alguns, na sua transmutação em outros movimentos políticos.

A descrição desses regimes de deslocamento das engrenagens do aparelho enunciativo - por meio das análises de cartazes de manifestação - seguiram um trajeto específico: partiu de Benveniste, para a compreensão da teoria da enunciação; passou por Charaudeau, para o entendimento dos modos enunciativos do discurso; e chegou em Maingueneau, na demonstração dos sistemas de citação sem autor.

Diante disso, pudemos ampliar a compreensão do funcionamento enunciativo e discursivo dos milhares de cartazes empunhados ao longo dos Protestos de Junho de 2013. Essas vozes-palavras empunhadas servem para nos lembrar a todo instante um $a$ priori democrático: que as ruas são espaços políticos e arenas de luta.

\section{Referências}

BENVENISTE, E. Problemas de linguística geral I. Campinas: Pontes, 2005.

CHARAUDEAU, D. Discurso político. São Paulo: Contexto, 2006.

MAINGUENEAU, D. A noção de hiperenunciador. In: Polifonia, Cuiabá, EdUFMT, n. 10, 2005, p. 75-97.

\footnotetext{
* Professor do Programa de Mestrado em Letras e do Mestrado em Gestão, Planejamento e Ensino da Universidade Vale do Rio Verde. Doutor em Linguística e Língua Portuguesa pela Unesp Araraquara. Líder do Grupo de Estudos Argumentare: Retórica, Discurso e Polêmicas Sociais.
} 